\title{
Antisense oligonucleotide treatment ameliorates alpha-1 antitrypsin-related liver disease in mice
}

\author{
Shuling Guo, ${ }^{1}$ Sheri L. Booten, ${ }^{1}$ Mariam Aghajan, ${ }^{1}$ Gene Hung, ${ }^{1}$ Chenguang Zhao, ${ }^{1}$ \\ Keith Blomenkamp, ${ }^{2}$ Danielle Gattis, ${ }^{1}$ Andrew Watt, ${ }^{1}$ Susan M. Freier, ${ }^{1}$ \\ Jeffery H. Teckman, ${ }^{2}$ Michael L. McCaleb, ${ }^{1}$ and Brett P. Monia ${ }^{1}$ \\ ${ }^{1}$ Antisense Drug Discovery, Isis Pharmaceuticals, Carlsbad, California, USA \\ 2Department of Pediatrics, St. Louis University School of Medicine, St. Louis, Missouri, USA.
}

\begin{abstract}
Alpha-1 antitrypsin deficiency (AATD) is a rare genetic disease that results from mutations in the alpha-1 antitrypsin $(A A T)$ gene. The mutant AAT protein aggregates and accumulates in the liver leading to AATD liver disease, which is only treatable by liver transplant. The PiZ transgenic mouse strain expresses a human $A A T(b A A T)$ transgene that contains the AATD-associated Glu342Lys mutation. PiZ mice exhibit many AATD symptoms, including AAT protein aggregates, increased hepatocyte death, and liver fibrosis. In the present study, we systemically treated PiZ mice with an antisense oligonucleotide targeted against $b A A T$ (AAT-ASO) and found reductions in circulating levels of AAT and both soluble and aggregated AAT protein in the liver. Furthermore, AAT-ASO administration in these animals stopped liver disease progression after short-term treatment, reversed liver disease after long-term treatment, and prevented liver disease in young animals. Additionally, antisense oligonucleotide treatment markedly decreased liver fibrosis in this mouse model. Administration of AAT-ASO in nonhuman primates led to an approximately $80 \%$ reduction in levels of circulating normal AAT, demonstrating potential for this approach in higher species. Antisense oligonucleotides thus represent a promising therapy for AATD liver disease.
\end{abstract}

\section{Introduction}

Alpha-1 antitrypsin (AAT) is a serum protease inhibitor mainly produced and secreted by hepatocytes. As a member of the serpin super family, AAT covalently binds to its protease target thereby eliminating protease activity. One of the main AAT targets is neutrophil elastase, which causes damage to lung connective tissue if its activity is uncontrolled (1). AAT deficiency (AATD) is a rare genetic disease caused by mutations in the AAT gene. There are two main phenotypes associated with this disease: (a) adult-onset emphysema due to loss of AAT activity and unchecked neutrophil elastase activity and (b) liver disease due to polymerization and retention of mutant AAT in liver (2-9). The AAT mutation that causes the most severe lung and liver disease is the Glu342Lys $(Z)$ point mutation. This mutation results in a "loop-sheet" conformation of the protein that favors protein aggregation and impairs secretion from the liver $(10,11)$. In homozygous individuals (referred to as individuals with PiZZ), the abnormal protein is largely retained inside hepatocytes and forms insoluble aggregates within the rough ER. These intracellular inclusions are believed to be hepatotoxic, and liver disease occurs with a bimodal onset in a subset of patients with PiZZ. In infancy/early childhood liver disease, the pathology often presents initially as neonatal jaundice and cholestasis, followed by progression to advanced fibrosis or cirrhosis in a subset of children. In adulthood, liver disease manifests as slowly progressive fibrosis, with an average age of diagnosis in the fifth decade, which is associated with increased risk of

Conflict of interest: Shuling Guo, Sheri L. Booten, Mariam Aghajan, Gene Hung, Chenguang Zhao, Danielle Gattis, Andrew Watt, Susan M. Freier, Michael L. McCaleb, and Brett P. Monia are employees and stockholders of Isis Pharmaceuticals. Citation for this article: J Clin Invest. 2014;124(1):251-261. doi:10.1172/JCI67968. cirrhosis and hepatocellular carcinoma $(\mathrm{HCC})(12,13)$. Although replacement therapy is available for lung disease by supplying plasma-derived AAT, the only treatment option for AATD liver disease is liver transplant. As a result, AATD liver disease is one of the most common causes of liver transplant in children (14).

Transgenic mouse models have been established to investigate AATD liver disease (15-18). PiZ mice harbor the human AAT (bAAT) genomic transgene with the $\mathrm{Z}$ mutation and exhibit $h A A T Z$ protein expression patterns resembling those in humans (19). As observed in patients with AATD liver disease, significant $Z$ protein aggregation and retention is observed in PiZ mouse liver that can be visualized with periodic acid-Schiff staining after diastase treatment (PAS-D) $(15,20)$. These PAS-D-positive aggregates, also known as globules, accumulate in the ER and cause ER stress (21-24), resulting in increased hepatic apoptosis in PiZ mice compared with that in wild-type animals. The magnitude of apoptosis correlates with $\mathrm{Z}$ protein aggregate content in the liver (25). This liver injury signal stimulates less damaged hepatocytes to proliferate to compensate for cell death, which in turn increases the incidence of $\operatorname{HCC}(26,27)$. In addition, globule-induced liver injury also leads to fibrosis in these mice (28-30). Since PiZ hepatocytes are not as healthy as normal hepatocytes due to the presence of globules, they have reduced tolerance to other stress conditions, including fasting, nonsteroidal antiinflammatory drugs, and surgical procedures such as partial hepatectomy (31-33). Because endogenous protease inhibitor genes are intact in PiZ mice, these mice have no lung abnormalities (15). Overall, PiZ mice are a valuable tool for the identification and evaluation of novel therapies for the treatment of AATD liver disease.

Because AATD liver disease is the result of toxic gain-of-function mutations, we hypothesized that reduction of levels of the mutant 

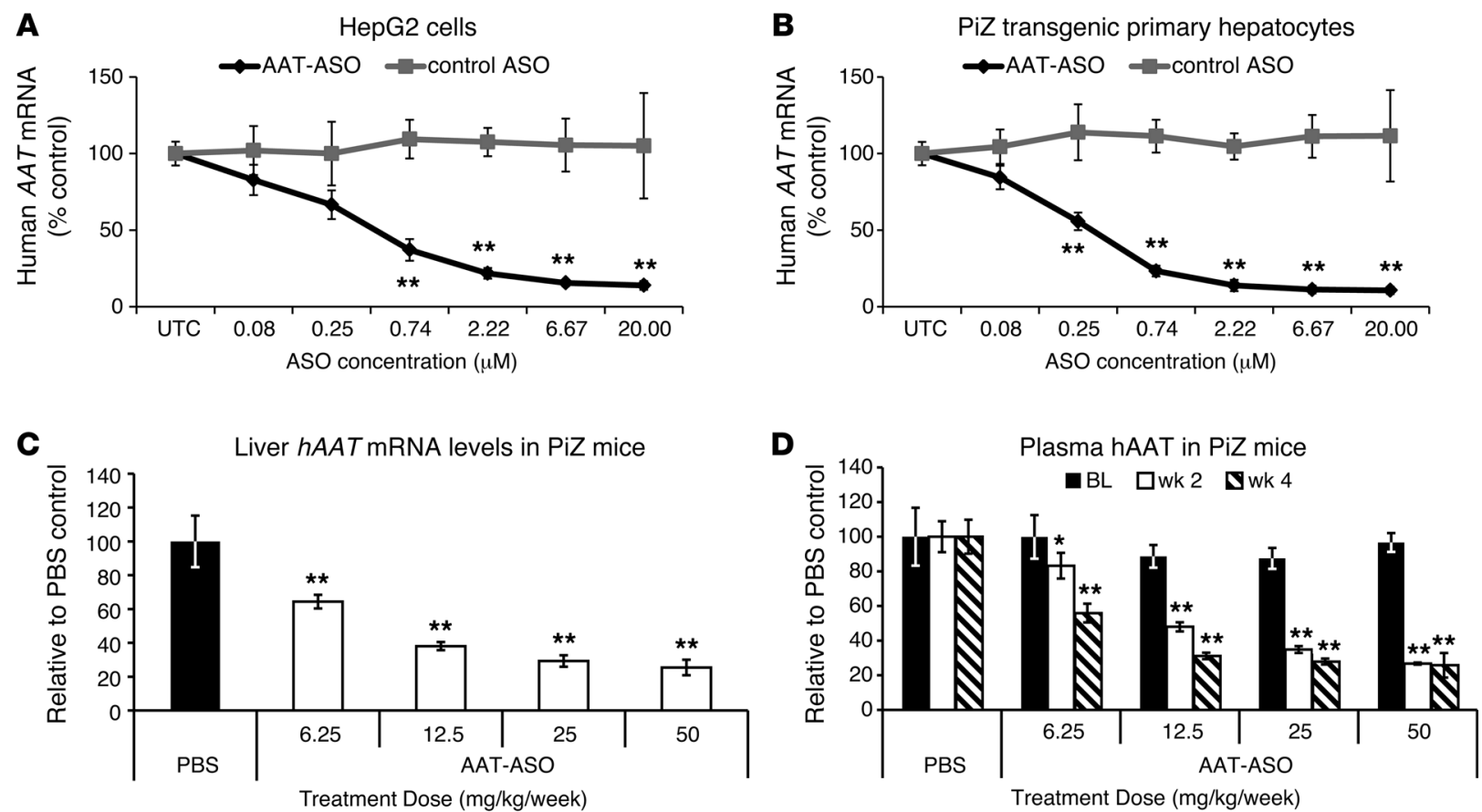

Figure 1

Characterization of an ASO that effectively reduces AAT levels in cells. (A) Dose-dependent reduction of $A A T$ mRNA in HepG2 cells. (B) Dose-dependent reduction of $h A A T$ mRNA in primary hepatocytes isolated from PiZ mice. Cells were electroporated in growth medium in the presence of AAT-ASO at the indicated concentrations and plated. Twenty-four hours after transfection, total cellular RNA was isolated and the amount of AAT mRNA present was quantitated using a qRT-PCR assay (TaqMan). Results represent mean $\pm \mathrm{SD}(n=3)$ compared to untransfected control (UTC). (C) Dose-dependent reduction of $h A A T$ mRNA levels in PiZ mice after AAT-ASO treatment. (D) Dose-dependent reduction of circulating hAAT protein in PiZ mice after AAT-ASO treatment. Six-week-old PiZ mice were treated for 4 weeks with the indicated doses of AAT-ASO via subcutaneous injection. $h A A T$ mRNA levels in livers were quantified by qRT-PCR (TaqMan), and plasma AAT levels were determined by an immunoturbidimetric method. Results represent mean $\pm \mathrm{SD}(n=4) .{ }^{*} P<0.05,{ }^{* *} P<0.01$ by 2-way ANOVA with Bonferroni's post-hoc tests for $A$, B, and D; 1-way ANOVA with Tukey's comparisons for $\mathbf{C}$.

AAT protein would slow or reverse intracellular protein aggregation in hepatocytes and alleviate hepatic disease symptoms. It was shown previously that a siRNA delivered using a recombinant adeno-associated virus vector reduced $Z$ protein production in $\mathrm{PiZ}$ mice during a short treatment period (34). To this end, we have generated second-generation antisense oligonucleotide (ASO) inhibitors complementary to the $h A A T$ gene. Here, we show that ASO targeted against $h A A T$ (AAT-ASO) is a potent AAT inhibitor in hepatic cells, PiZ mice, and cynomolgus monkeys. AAT-ASO treatment in adult PiZ mice significantly reduced soluble and aggregated AAT protein accumulation in liver and reduced liver fibrosis. When administered to young PiZ mice, AAT-ASO treatment protected mice from globule formation in the liver and subsequent globule-induced liver injury.

\section{Results}

AAT-ASO treatment reduces AAT $m R N A$ levels in buman bepatocytes and hepatocytes isolated from PiZ mice. Antisense technology exploits a cellular RNase $\mathrm{H}$ mechanism to degrade the target mRNA in an mRNA-ASO duplex, which ensures specificity. Second-generation ASOs are potent and specific inhibitors of gene expression that are well tolerated in rodents, primates, and humans (35). Over 1,500 second-generation, 2'-O-methoxyethyl ASOs (35), each 20 bases in length and designed to target the $h A A T$ gene, were synthesized, and their ability to reduce levels of $A A T$ mRNA was tested in
HepG2 cells, a human HCC cell line. Numerous ASOs were found to be active in reducing $A A T$ mRNA levels (data not shown); however, one particular ASO (AAT-ASO), complementary to a region in exon 5 within the $3^{\prime}$ untranslated region of the $A A T$ gene, was found to be particularly potent (Figure 1A). AAT-ASO is $100 \%$ complementary to both the human and monkey (Rhesus) AAT gene but contains 6 mismatches to the mouse AAT gene. AAT-ASO activity was also confirmed in primary hepatocytes isolated from $\mathrm{PiZ}$ transgenic mice (Figure 1B). Electroporation of AAT-ASO into these cells produced significant reductions in AAT mRNA levels in a dose-dependent manner $\left(\mathrm{IC}_{50}=0.5 \mu \mathrm{M}\right.$ in HepG2 cells and 0.4 $\mu \mathrm{M}$ in PiZ transgenic hepatocytes). Importantly, the mismatched control ASO did not affect the expression of the AAT gene.

AATD liver disease occurs almost exclusively in patients with mutations in both alleles, and the majority of the clinical cases of AATD liver disease are patients with PiZZ. Other mutations can also cause protein aggregation and lead to liver disease, such as Mmalton ( $\left.\Delta^{52} \mathrm{Phe}\right)(36)$. The $3^{\prime}$ untranslated region target sequence for AAT-ASO lies outside regions of known AAT mutations, and no known single nucleotide polymorphisms have been reported within the AAT-ASO binding site. Thus, AAT-ASO is predicted to be perfectly complementary to all known mutant forms of $A A T$.

AAT-ASO treatment results in a dose-dependent reduction of $h A A T$ protein in PiZ mice. In order to evaluate the in vivo activity of AATASO, 6-week-old PiZ mice were treated with 6.25, 12.5, 25, or 
A

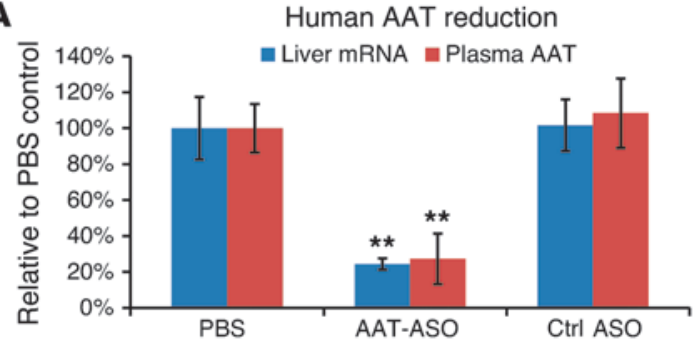

C

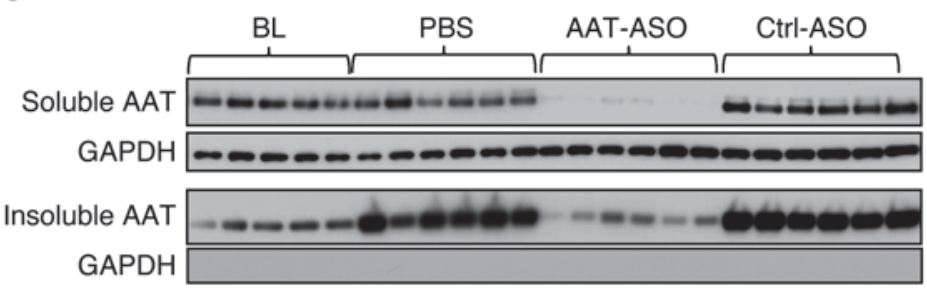

B
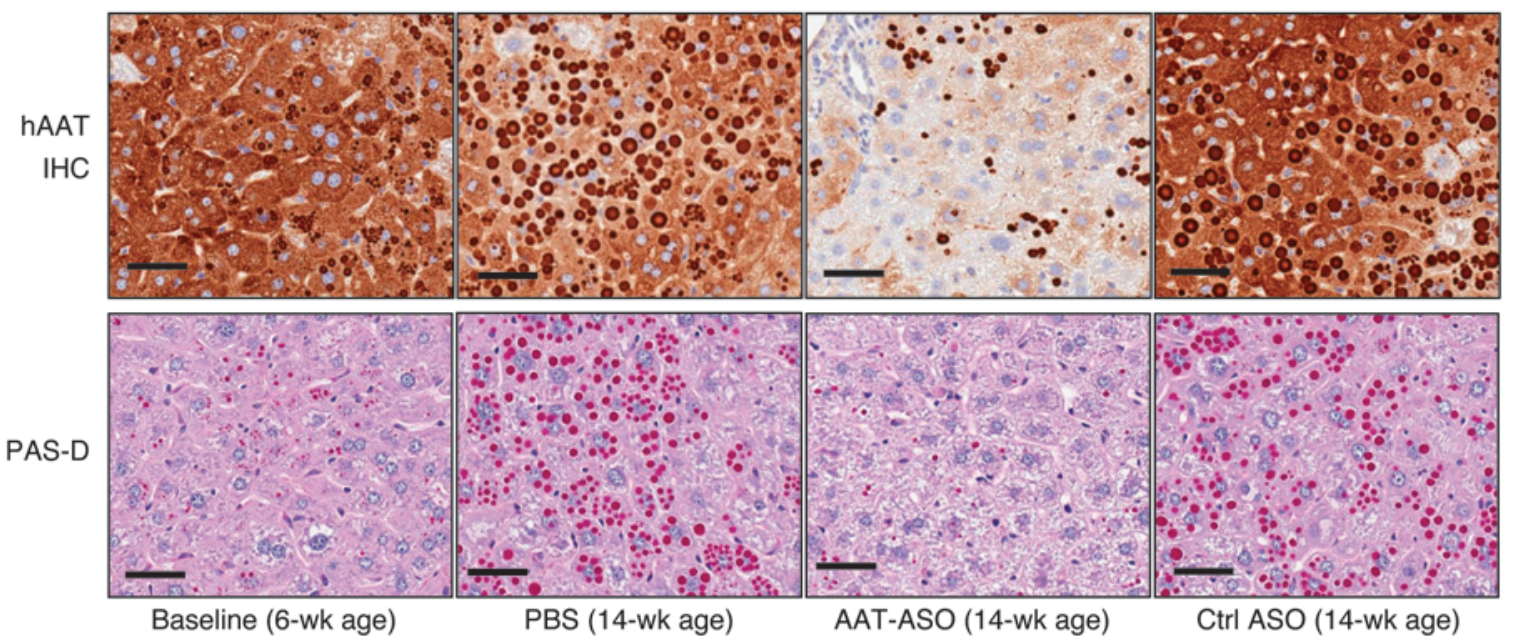

D

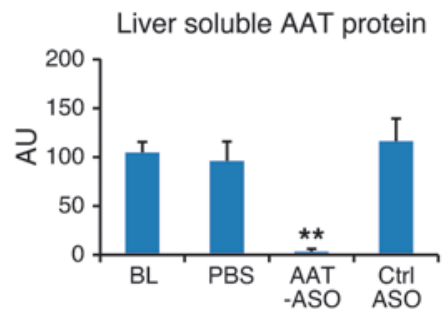

E

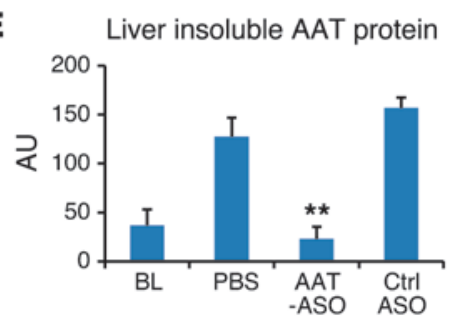

Figure 2

Soluble and aggregated AAT protein levels were reduced in PiZ mouse livers after AAT-ASO treatment. (A) Six-week-old PiZ mice were treated for 8 weeks with PBS, $50 \mathrm{mg} / \mathrm{kg} / \mathrm{wk}$ AAT-ASO, or control ASO via subcutaneous injection. $h A A T$ mRNA levels in livers were quantified by qRT-PCR (TaqMan), and plasma AAT protein levels were determined by clinical chemistry analyzer. (B) IHC staining for AAT protein and PAS-D staining in liver. Scale bar: $50 \mu \mathrm{m}$. (C) Soluble and insoluble fractions from PiZ livers were analyzed by Western blot analysis with an anti-hAAT antibody. GAPDH was used as a loading control. BL, baseline. (D) Quantitation of soluble and (E) insoluble AAT protein from C. Results represent mean \pm SD ( $n=5-6$ per group). ${ }^{* \star} P<0.01$ by 1 -way ANOVA with Tukey's comparisons.

$50 \mathrm{mg} / \mathrm{kg} / \mathrm{wk}$ AAT-ASO for 4 weeks by subcutaneous injection. Plasma levels of hAAT protein were determined at baseline, 2 weeks after treatment, and at the end of treatment. Hepatic $h A A T$ mRNA levels were determined at study termination. A dose-dependent reduction of $h A A T$ mRNA and plasma protein levels was observed following treatment with AAT-ASO (Figure 1, C and D). At the $50 \mathrm{mg} / \mathrm{kg} /$ wk dose, $70 \%-80 \%$ reduction in both $h A A T \mathrm{mRNA}$ and plasma hAAT protein levels was observed. We have shown previously that mismatches in ASOs greatly reduce their activity $(37,38)$. Since AAT-ASO has 6 mismatches to mouse AAT, we did not expect any significant effect on mouse AAT. As expected, human-specific AAT-ASO treatment had no effect on mouse AAT liver mRNA levels or plasma protein levels (Supplemental Figure 1, A and B; supplemental material available online with this article; doi:10.1172/ JCI67968DS1). No dramatic effects were observed on hepatocyte- specific genes, such as albumin or transthyretin, or plasma albumin levels (Supplemental Figure 1, C-E) after AAT-ASO treatment. Administration with a second ASO targeting $h A A T$ resulted in similar target reductions (Supplemental Figure 4A), while treatment with a control ASO caused no reduction in $h A A T \mathrm{mRNA}$ or protein levels (Supplemental Figure 2, A and B).

AAT-ASO treatment reduces liver protein aggregates in PiZ mice. To evaluate the effect of AAT-ASO on accumulation of AAT protein aggregates in PiZ mouse livers, 6-week-old mice were treated with PBS, $50 \mathrm{mg} / \mathrm{kg} /$ wk AAT-ASO, or control ASO for 8 weeks. $h A A T$ mRNA and plasma hAAT protein levels were significantly reduced in AAT-ASO-treated animals compared with those in PBS- or control ASO-treated animals (Figure 2A, $P<0.01$ with both comparisons). Liver pathology was evaluated by PAS-D staining to visualize $\mathrm{Z}$ protein aggregates and by immunohistochemistry (IHC) 
A

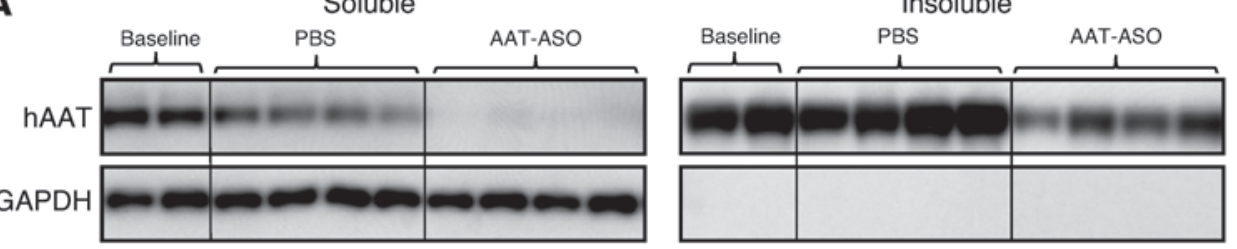

B

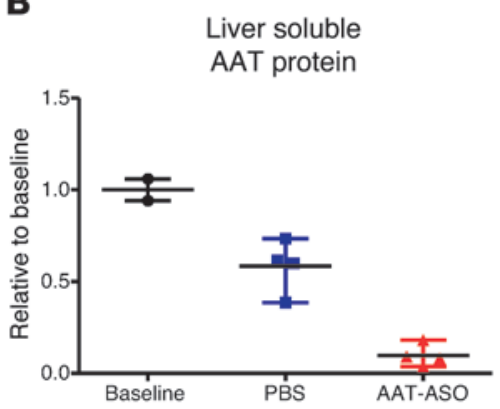

C

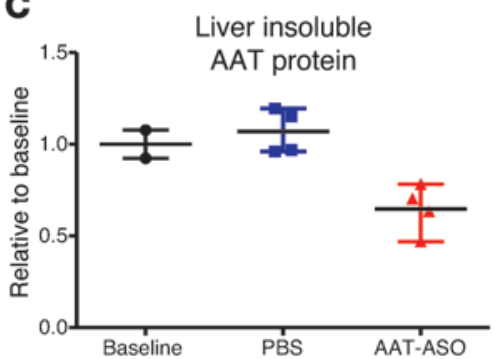

D
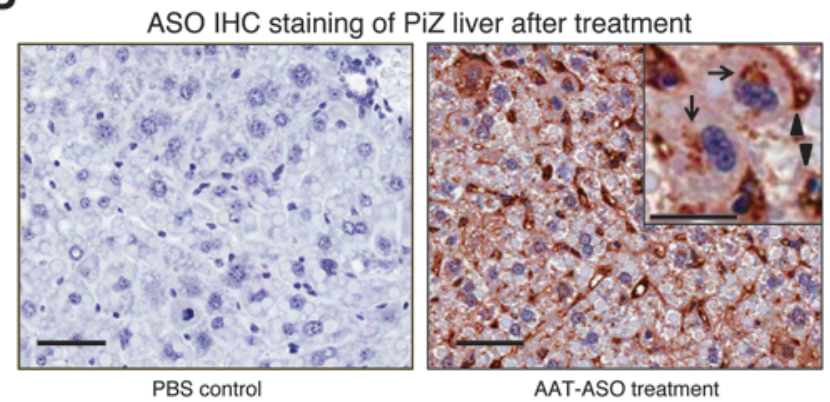

$\mathbf{E}$

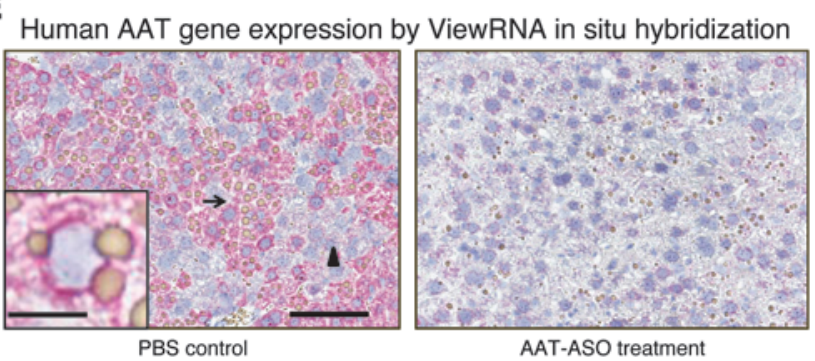

Figure 3

AAT-ASO treatment reversed liver globule accumulation and reduced $h A A T$ in all hepatocytes in PiZ mice. (A) Sixteen-week-old PiZ mice were treated for 20 weeks with $50 \mathrm{mg} / \mathrm{kg} / \mathrm{wk}$ AAT-ASO via subcutaneous injection. Soluble and insoluble fractions from PiZ livers were analyzed by Western blot analysis with an anti-hAAT antibody. GAPDH was used as a loading control. (B) Quantitation of liver soluble AAT Western blot data shown in A. (C) Quantitation of liver insoluble AAT Western blot data shown in A. (D) ASO uptake by hepatocytes in PiZ mice. ASO was visualized by an antibody reactive to the ASO backbone. Arrows indicates perinuclear vesicle staining in hepatocytes; arrowheads indicates nonparenchymal cells. Scale bar: $50 \mu \mathrm{m} ; 20 \mu \mathrm{m}$ (inset). (E) hAAT transcript visualized by in situ hybridization (QuantiGene ViewRNA, Affymetrix). The arrow indicates a globule-containing area; the arrowhead indicates a globule-devoid area. Scale bar: $100 \mu \mathrm{m} ; 20 \mu \mathrm{m}$ (inset). Results represent mean \pm range ( $n=2$ for baseline, $n=4$ for treatment groups).

using an antibody specific to hAAT to visualize both soluble and aggregated $\mathrm{Z}$ protein (34). After AAT-ASO treatment, there was a significant reduction in hAAT in the liver, as shown by IHC. PAS-D staining also demonstrated a dramatic decrease in the size and number of hAAT aggregates in the livers of ASO-treated mice (Figure 2B). Percentages of area stained positively for PAS-D were quantitated with Aperio software and is shown in Supplemental Figure 3. AAT-ASO treatment resulted in approximately $70 \%$ reduction in PAS-D-positive area compared with that of the PBS treatment group. Treatment with control ASO had no significant effect on PAS-D staining $(P>0.05)$.

To confirm the reduction of liver hAAT aggregates after AATASO treatment, PiZ mouse livers were homogenized, and the soluble and insoluble hAAT fractions were separated (39). The soluble fraction corresponds to nonaggregated mutant hAAT within hepatocytes, and the insoluble fraction represents mutant hAAT protein that has aggregated into insoluble globules within the ER. As measured by Western blot analysis, AATASO treatment resulted in over $90 \%$ reduction of soluble AAT and approximately $80 \%$ reduction of insoluble AAT in PiZ liv- ers. Again, control ASO treatment did not affect either soluble or insoluble AAT levels (Figure 2, C-E). Some minor discrepancy between PAS-D staining quantification (70\% aggregates reduction) and steady-state levels of insoluble protein determined by Western blot ( $~ 80 \%$ reduction in insoluble protein) was observed, which could be due to differences in sensitivity of these two measurements. Nonetheless, both measurements indicate that AAT-ASO treatment significantly reduced liver AAT aggregates $(P<0.01$ compared with PBS treatment group or control ASO treatment group). A second hAAT ASO (AATASO2) treatment resulted in similar reductions of soluble and insoluble AAT protein in liver, as determined by histological staining and Western blot (Supplemental Figure 4).

Comparing the effects of AAT-ASO treatment to baseline values, it is clear that AAT-ASO treatment stopped further accumulation of globules but did not reduce the liver globule load relative to baseline levels during this 8-week treatment period (Figure 2B; Figure 2, C and E; and Supplemental Figure 3, $P>0.05$ when AAT-ASO treatment group was compared to baseline). In order to address the question of whether AAT-ASO treatment can reverse liver globule accumu- 

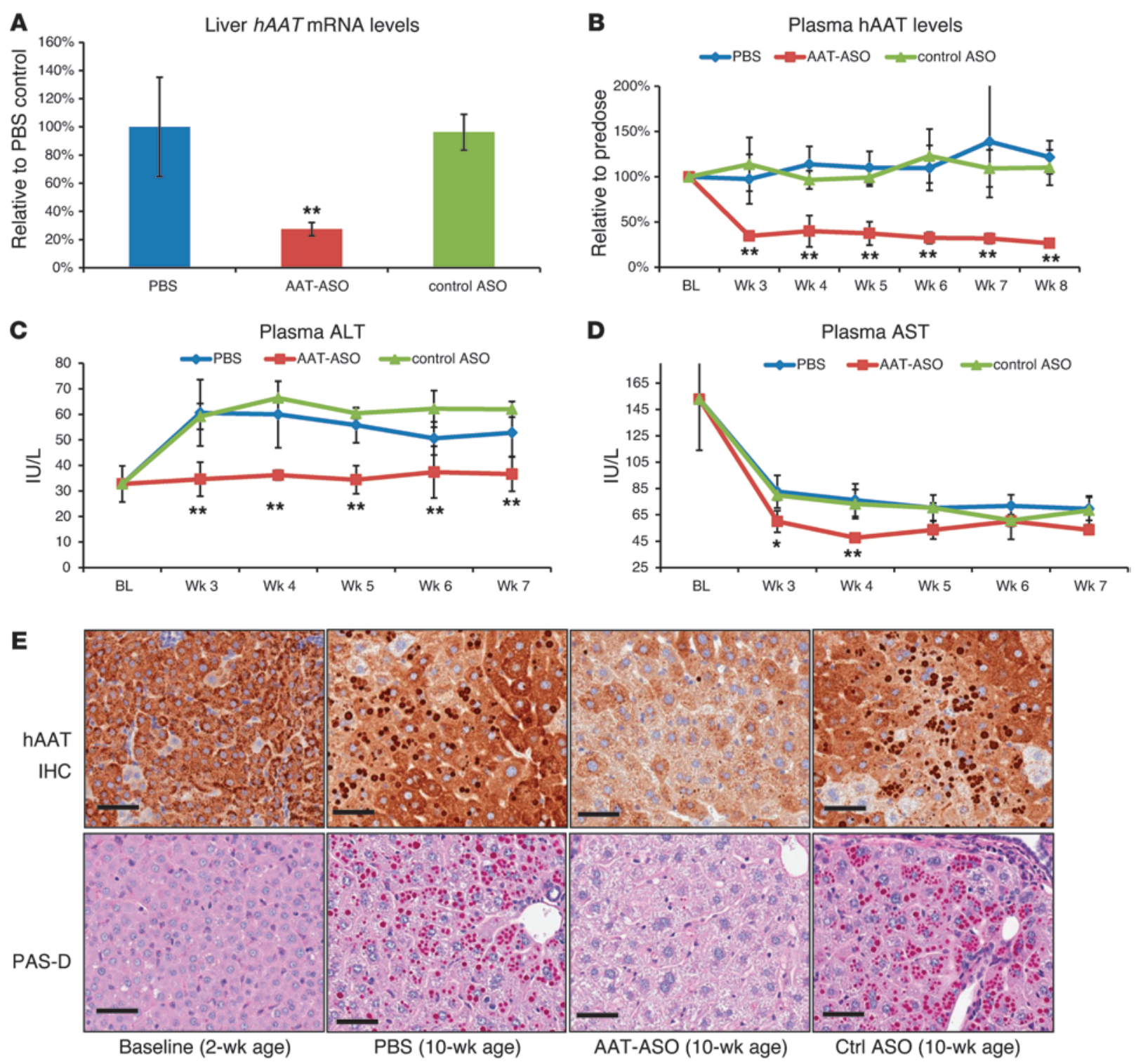

Figure 4

AAT-ASO treatment prevented $Z$ protein aggregate formation and liver injury in young PiZ mice. Two-week-old PiZ mice were treated for 8 weeks with PBS, $50 \mathrm{mg} / \mathrm{kg} /$ wk AAT-ASO, or control ASO via subcutaneous injection. (A) $h A A T$ mRNA reduction in livers was quantified by qRT-PCR (TaqMan). (B) Plasma hAAT level reduction was determined using a clinical chemistry analyzer. (C) Plasma ALT and (D) plasma AST levels were monitored at indicated time points. (E) Liver AAT protein levels were measured by IHC before and after treatment. Liver PAS-D staining before and after treatment (representative pictures from male groups were shown). Scale bar: $50 \mu \mathrm{m}$. Results represent mean \pm SD $(n=4-5$, including both male and female mice). ${ }^{*} P<0.05,{ }^{* *} P<0.01$ by 1 -way ANOVA for $\mathbf{A}$ and repeated-measures 2 -way ANOVA for B-D when AAT-ASO treatment group was compared with control ASO treatment group.

lation, 16-week-old PiZ mice were administered with PBS or AATASO for 20 weeks. At this disease stage, liver globule accumulation slows down dramatically, as shown by the fact that the levels of liver insoluble AAT were comparable between baseline and PBS treatment groups (Figure 3, A-C, and Supplemental Figure 5). However, AATASO treatment dramatically reduced both liver soluble AAT ( $90 \%)$ and insoluble AAT ( $40 \%)$ compared with those at baseline (Figure 3, A-C), indicating reversal of liver globule accumulation.

Mutant $\mathrm{Z}$ protein aggregate formation in PiZ livers is heterogeneous across the liver lobes, as reported previously (1, 32). Using an antibody generated against the phosphorothioate backbone of
ASOs, we sought to characterize the uptake and distribution of ASOs in PiZ livers and saw that both globule-containing cells and globule-devoid cells took up ASOs with relatively uniform distribution (Figure 3D). As previously reported, ASO staining is prominent in hepatocytes and in nonparenchymal cells, including endothelial cells and Kupffer cells. ASO accumulates mainly in perinuclear vesicles in hepatocytes $(40,41)$. Interestingly, in situ hybridization analysis showed that $A A T$ transcripts also display a heterogeneous expression pattern in PiZ livers, with higher expression in globule-containing areas than globule-devoid areas. AAT-ASO treatment markedly reduced levels of $h A A T \mathrm{mRNA}$ in all hepatocytes (Figure 3E). 
A

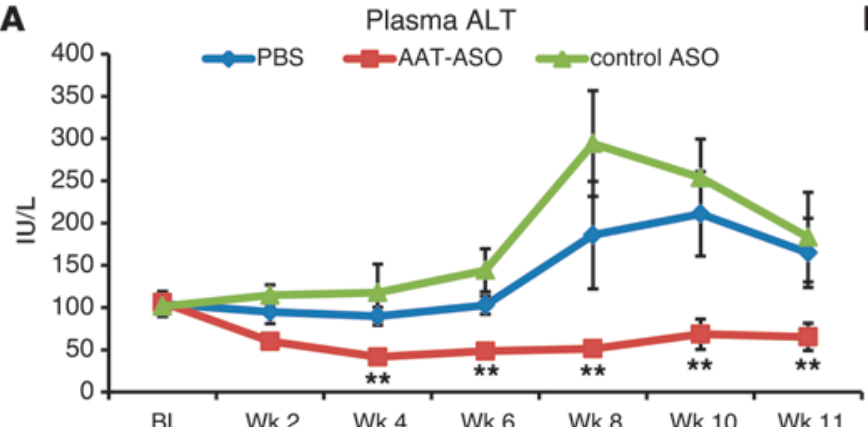

C

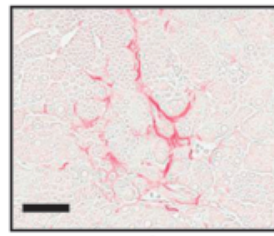

PBS

E

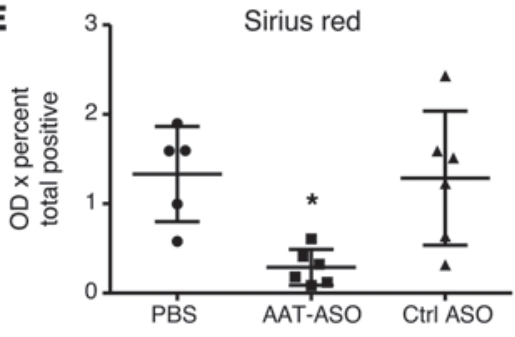

H
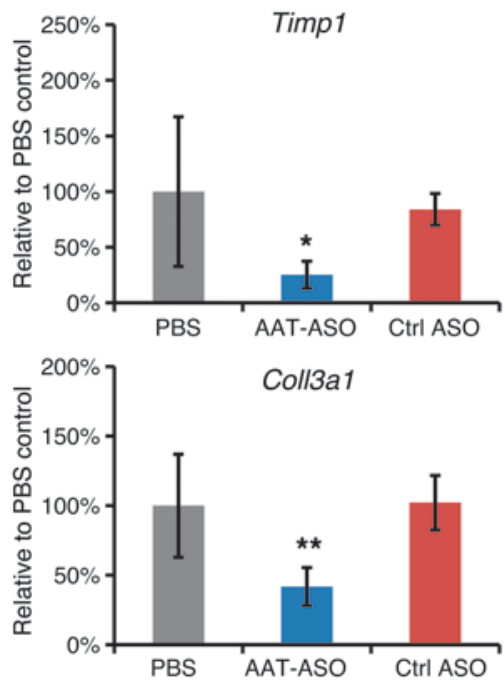

Ctrl ASO
B

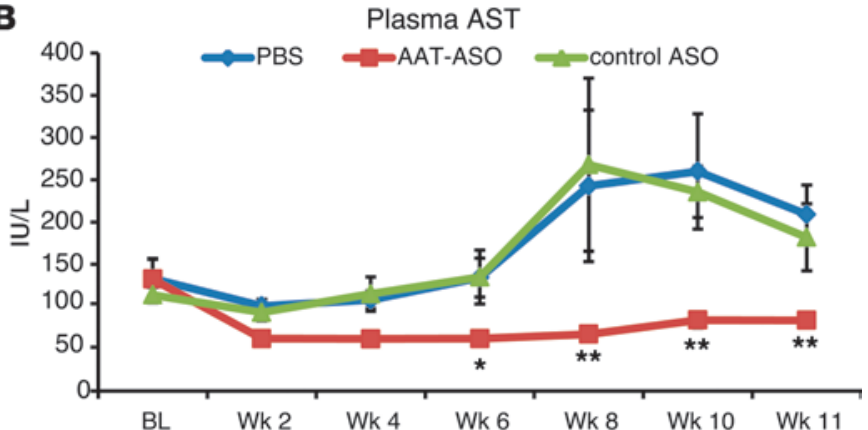

D
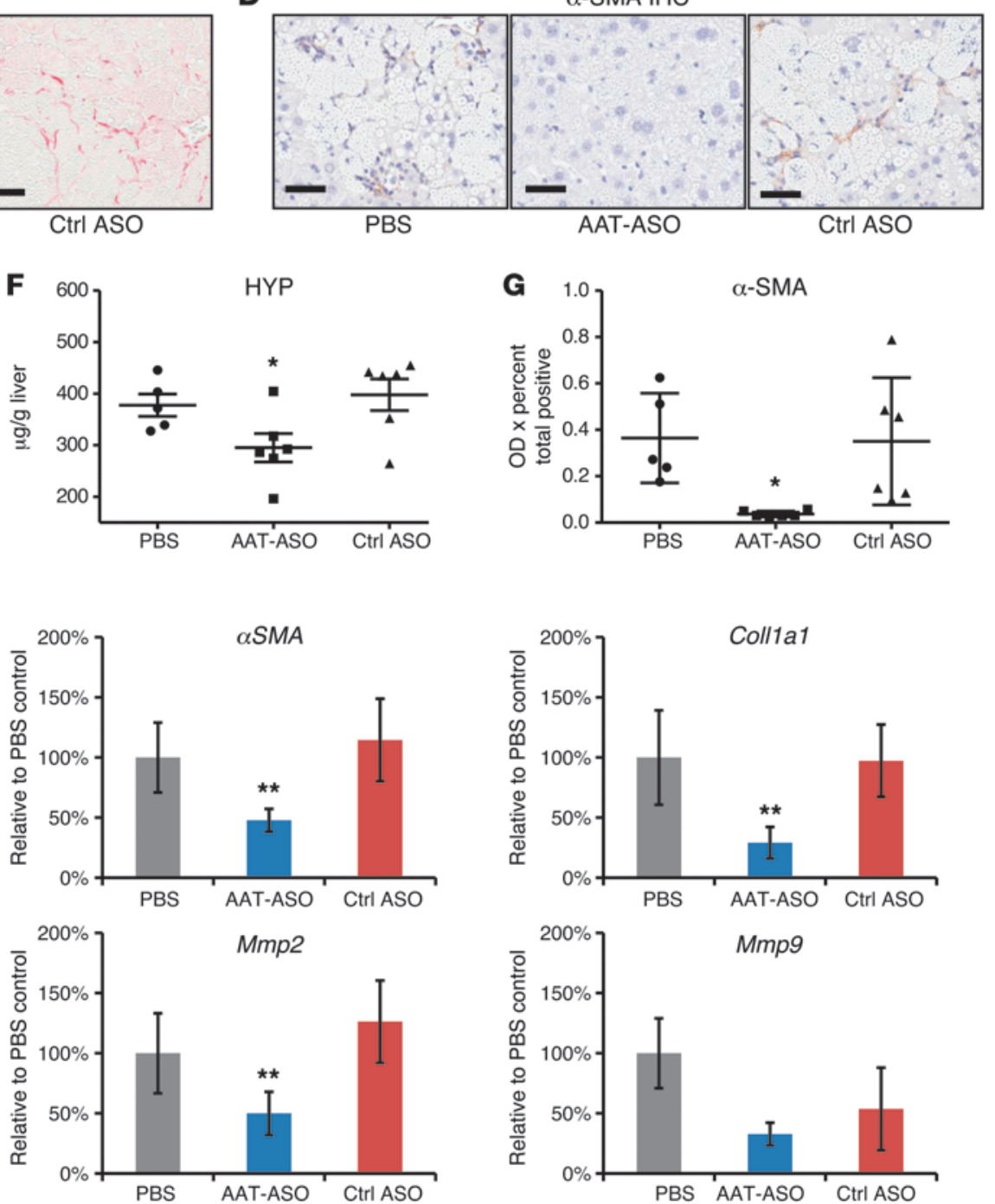

Figure 5

AAT-ASO treatment significantly reduced liver injury and fibrosis in PiZZ mice. Five-week-old PiZZ mice were treated for 11 weeks with PBS, AAT-ASO, or control ASO via subcutaneous injection. (A) Plasma ALT levels and (B) plasma AST levels were monitored throughout the treatment period. Significant reduction of (C) Sirius red staining (quantitation in E), (F) hydroxyproline content, and (D) $\alpha$-SMA staining (quantitation in G) in liver sections was observed after AAT-ASO treatment. Scale bar: $50 \mu \mathrm{m}$. (H) Liver fibrosis-related gene mRNA levels were quantified by qRT-PCR (TaqMan). Results represent mean \pm SD in all panels except $\mathbf{F}$, which is shown as mean \pm SEM $(n=5-6)$. ${ }^{*} P<0.05,{ }^{*} P<0.01$ by repeated-measures 2-way ANOVA for $\mathbf{A}$ and $\mathbf{B}$ and 1-way ANOVA with Tukey's comparisons for $\mathbf{E}-\mathbf{H}$ when AAT-ASO treatment group was compared with control ASO treatment group. 
A

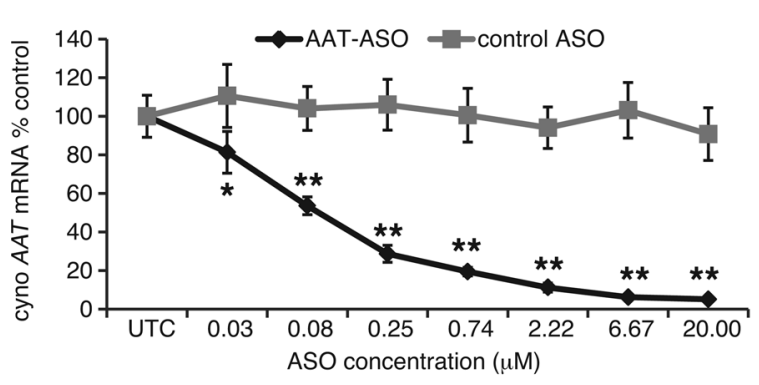

B Liver $A A T$ mRNA reduction

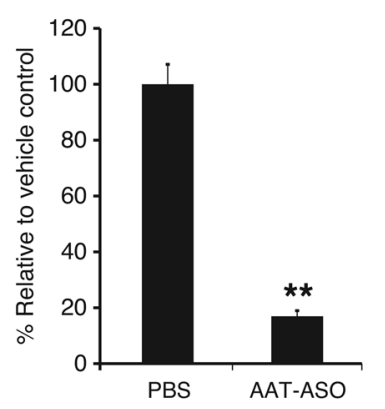

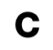

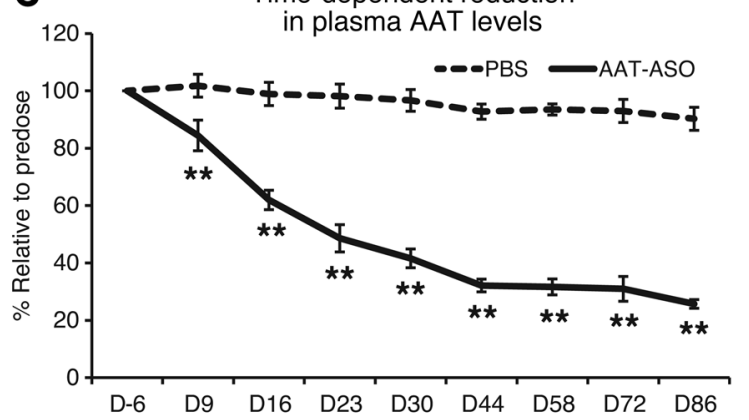

\section{Figure 6}

Robust AAT reduction in cynomolgus hepatocytes and in vivo after AAT-ASO treatment. (A) Dose-dependent reduction of $A A T$ mRNA in primary hepatocytes isolated from cynomolgus monkeys. Cells were electroporated in growth medium in the presence of AAT-ASO at the indicated concentrations and plated. Twenty-four hours after transfection, total cellular RNA was isolated and the amount of $A A T$ mRNA present was quantitated using a qRT-PCR assay (TaqMan). Results represent mean $\pm \mathrm{SD}(n=3)$ compared to untransfected control. (B) $A A T$ mRNA levels in livers. (C) Plasma AAT protein levels during the treatment period. Cynomolgus monkeys were treated with AAT-ASO for 12 weeks at $25 \mathrm{mg} / \mathrm{kg} 3$ times in the first week and twice a week in weeks 2 to 12 . Liver total RNA was purified, and qRT-PCR was carried out to determine the levels of $A A T$ mRNA in the liver. The plasma protein levels were measured by the immunoturbidimetry method using a clinical analyzer. Results represent the mean $\pm \operatorname{SD}(n=4) .{ }^{*} P<0.05,{ }^{* \star} P<0.01$ by 2-way ANOVA with Bonferroni's post-hoc tests for $\mathbf{A}$ and $\mathbf{C}$ and Student's $t$ test for $\mathbf{B}$.
AAT-ASO treatment prevents liver aggregate formation in young PiZ mice. At birth, livers of PiZ mice were free of AAT aggregates. As mice aged, $\mathrm{Z}$ protein accumulated and formed aggregates in the livers. By 2 weeks of age, small PAS-D-positive aggregates could be detected (Figure 4E). We treated 2-week-old PiZ mice with PBS, AAT-ASO, or control ASO, before significant accumulation of AAT aggregates had occurred. As observed in adult mice, 8-week AAT-ASO treatment significantly reduced liver mRNA levels of $h A A T$ and plasma hAAT by $70 \%$ to $80 \%$ (Figure 4 , A and B, $P<0.01$ ). Control ASO treatment did not affect either $h A A T$ mRNA or hAAT protein levels throughout the treatment $(P>0.05$ when compared to PBS treatment group), analogous to that seen in adult mice (Figure $2 \mathrm{~A}$ ). Similar to most human patients with AAT deficiency, young PiZ animals showed only mild elevations in liver enzymes (such as alanine transaminase [ALT] and aspartate aminotransferase [AST]) compared with non-PiZ controls. While control ASO treatment did not affect ALT/AST levels, treatment of these young PiZ animals with AAT-ASO significantly lowered ALT levels, and this reduction was maintained throughout the course of the study (Figure 4C, $P<0.01$ compared with control ASO treatment group). A similar trend of reduction was also observed with AST levels after AAT-ASO treatment (Figure 4D). IHC analysis demonstrated that liver AAT protein expression was greatly reduced in the AAT-ASO treatment group compared with that in the PBS group or control ASO treatment group (Figure 4E). In addition, the PBS or control ASO treatment groups showed extensive PAS-D-positive globules in the livers at 10 weeks of age, whereas globules were nearly absent in the AAT-ASO treatment group (Figure 4E). Similar effects were observed in both male and female PiZ mice (representative IHC and PAS-D micrographs are shown in Figure 4E). Thus, treatment with AAT-ASO prevented AAT protein aggregate formation and liver injury in these young mice.

AAT-ASO treatment ameliorates liver injury and fibrosis in PiZZ mice. It has been demonstrated that AAT aggregates in the liver lead to chronic liver injury and eventually liver fibrosis $(15,29,30)$. PiZZ mice contain 2 alleles of the human $Z$ mutant transgene and express higher levels of $Z$ protein than PiZ mice. These mice show an ALT/AST spike as well as tissue inhibitor of metalloprotease (TIMP1) upregulation when they are approximately 3 months old, and fibrosis is established around 4 months of age (Supplemental Figure 6). To evaluate the effect of AAT-ASO treatment on liver fibrosis, we treated 5-week-old PiZZ mice for 11 weeks with PBS, AAT-ASO, or control ASO $(50 \mathrm{mg} / \mathrm{kg} / \mathrm{wk})$ subcutaneously. Elevations in markers of liver toxicity, ALT and AST, were observed in PBS- and control ASO-treated PiZZ mice at around 3 months of age, likely due to globule-induced hepatocyte apoptosis. However, AAT-ASO treatment significantly prevented elevations in ALT/ AST enzymes throughout the treatment period (Figure 5, A and $\mathrm{B}, P<0.05$ when compared to control ASO treatment group). Furthermore, Sirius red staining demonstrated dramatically less collagen fiber deposition in the AAT-ASO-treated livers as compared with PBS- or control ASO-treated livers (representative images are shown in Figure 5C; images from each individual animal are shown in Supplemental Figure 7, A-C; quantitation is shown in Figure 5E). PiZZ liver hydroxyproline content was also significantly reduced in AAT-ASO-treated mice (Figure 5F, $P<0.05$ when compared to control ASO treatment group). The hydroxyproline levels in AAT-ASO-treated animals were comparable to those of wild-type C57BL/6 mice of similar age (data not shown). Staining for $\alpha$-SMA, a marker of activated stellate cells, was similarly reduced in the AAT-ASO treatment group compared with that in the control ASO treatment group (Figure 5, D and G). Reduction of $\alpha$-SMA was confirmed by Western blot analysis (Supplemental Figure 7D). To further demonstrate the antifibrotic potential of AAT-ASO in PiZZ mice, mRNA expression analysis was conducted on a set of fibrosis-related genes in controls and AAT-ASO-treated mice. Compared with that in control ASO-treated animals, AATASO treatment dramatically reduced the expression levels of fibrosis-related genes in the livers. These genes included Timp1, $\alpha S M A$, 
Col1a1 and Col3a1, and metalloproteinases Mmp2 and Mmp9 (Figure $5 \mathrm{H})$. No significant differences were observed between PBS and control ASO treatment groups with these fibrosis end points $(P>0.05)$. These data strongly indicate that AAT-ASO treatment ameliorates globule-induced liver injury and the subsequent development of liver fibrosis in PiZZ mice. Treatment with a second hAAT ASO (AAT-ASO2) resulted in similar reductions of ALT/AST and liver fibrosis in PiZZ mice (Supplemental Figure 8).

AAT-ASO administration decreases AAT production in cynomolgus monkeys. The AAT-ASO evaluated in PiZ mice is complementary to human and monkey $A A T$ mRNA. In isolated cynomolgus hepatocytes, AAT-ASO reduced $A A T$ gene expression at concentrations similar to those observed in human cells ( $\mathrm{IC}_{50}$ of $0.1 \mu \mathrm{M}$ for cynomolgus hepatocytes, Figure 6A). To determine the potential for this AAT-ASO to reduce AAT levels in nonhuman primates, a 12 -week cynomolgus monkey study was conducted in which AATASO was administered subcutaneously at $25 \mathrm{mg} / \mathrm{kg} 3$ times for the first week and twice a week for weeks 2 through 12 . AAT-ASO treatment was well tolerated and resulted in an approximately $80 \%$ reduction of liver $A A T$ mRNA levels at the end of the study (Figure $6 \mathrm{~B})$. Plasma AAT levels in untreated animals were relatively stable throughout the course of the study. However, treatment with AAT-ASO produced a time-dependent reduction of plasma AAT levels starting as early as day 9 (approximately 16\% reduction) after initiation of treatment and with maximal effects (approximately $70 \%$ reduction) observed between days 44 and 86 (Figure 6C). These results demonstrate that AAT-ASO is a potent inhibitor of $A A T$ expression in cynomolgus monkeys and suggests that it has the potential to reduce toxic levels of mutant $A A T$ expression in patients with AATD liver disease.

\section{Discussion}

In this report, we demonstrate that an ASO targeting AAT mRNA significantly reduces $A A T$ mRNA levels in cells and generates reproducible and robust reductions in liver $A A T$ mRNA and protein levels in PiZ mice and normal cynomolgus monkeys. AATD is a rare genetic disease that remains underdiagnosed despite the existence of a number of diagnostic tools, including the measurement of serum or plasma AAT protein levels, AAT protein phenotyping using isoelectric focusing gel, and $A A T$ genotyping (5, 6, $12,42)$. The PiZ mutation is believed to have arisen from a single founder about 2,000 years ago in the Viking population (43). In the United States, about $2 \%$ of the population is heterozygous for the $Z$ allele, and approximately $0.05 \%$ or 150,000 people are homozygous (PiZZ) (12). About $10 \%$ of children with PiZZ develop early-onset liver disease (44); over one-third of adult patients with PiZZ have cirrhosis at the time of death (45). However, most patients with PiZZ have fairly normal liver function tests and no or minimal symptoms of liver disease. In a recent study with 647 patients with PiZZ, mean AST and ALT levels were just above the upper limit of normal and within normal range, respectively (46). This suggests that genetic and/or environmental factors influence the onset and the severity of the liver disease. The nature of these factors is still largely unknown. It was reported that male gender and obesity predispose adult patients with PiZZ to advanced liver diseases (47). A delay in intracellular degradation of the mutant protein may also play an important role in liver disease development (24). Identification of these factors will help our understanding of this disease and define the patients who will likely require therapy.
In part due to limited understanding of the natural history of AATD liver disease and lack of reliable biomarkers to monitor liver disease progression before severe fibrosis, cirrhosis, or HCC occurs, there are no clinically approved treatments for AATD liver disease except liver transplantation. A number of potential intervention methods have been investigated in animal models. $Z$ protein aggregation results in ER stress, which activates the autophagy pathway to clear the aggregates $(48,49)$. Carbamazepine (CBZ) promotes autophagy-mediated protein degradation. In PiZ mice, CBZ treatment reduced hepatic aggregate load and fibrosis (29). It will be interesting to see whether similar effects can be achieved in patients with PiZZ at acceptable doses. Treatment with patient-derived induced pluripotent stem cells combined with zinc finger-mediated homologous recombination and in vitro differentiation (50), treatment with siRNA or microRNA to reduce $Z$ protein production $(34,51)$, inhibition of $Z$ protein aggregation by targeting $\beta$-sheet $A$ (52), and use of chaperones (53) have all been tested in cell-based or animal models. However, the practical utility of these approaches in patients with a chronic disease like AAT-related liver disease needs to be established. In contrast, an ASO of similar chemical modification as that used in our studies has demonstrated long-term therapeutic utility for the treatment of familial hyperlipidemia $(54,55)$.

In adult PiZ mice with established AAT pathology, AAT-ASO was internalized by both globule-containing cells and globule-devoid cells, causing a robust reduction in the expression of the mutant $A A T$ gene. The efficacy was maintained during 5 months of in vivo treatment. Significant reductions in both the soluble and aggregated AAT protein levels in the livers of AAT-ASO-treated PiZ mice demonstrate the benefit of directly preventing mutant gene expression. AAT-ASO treatment stopped disease progression and reversed liver disease in PiZ mice. Importantly, chronic reduction of AAT aggregates diminished the development of hepatic fibrosis. When AAT-ASO treatment of PiZZ mice was initiated at 2 weeks of age, liver AAT aggregate formation and subsequent elevations of liver enzymes were prevented. These findings support the proposition that AAT-ASO could be used in pediatric patients with PiZZ with deteriorating liver disease, in addition to adult patients with PiZZ. By eliminating the toxic protein in adult and pediatric patients with PiZZ, AAT-ASO treatment may prevent and reverse liver disease progression, avoiding the need for liver transplant.

In patients with PiZZ, serum AAT levels are approximately $10 \%-15 \%$ of normal subjects due to intracellular aggregation. In addition, the low level of mutant protein present in sera of patients with PiZZ has impaired binding to neutrophil elastase (56). $Z$ protein aggregates exhibit proinflammatory and neutrophil chemoattractant activity and have been detected in the lungs of patients with PiZZ (57). It has been hypothesized that the presence of $Z$ aggregates in the lungs of patients with PiZZ worsens lung disease by recruiting neutrophils (36). On the other hand, $A A T$-null patients develop emphysema but are free of liver diseases. In some cases, emphysema occurs with an earlier onset in $A A T$-null patients than in patients with PiZZ, which suggests that residual $Z$ protein may protect lung function to some extent (58). The number of $A A T$-null patients is very small, so these data must be interpreted with caution. Treatment of patients with PiZZ with AAT-ASO should reduce $Z$ protein production and improve liver disease. Whether this treatment increases risk of lung disease needs to be carefully evaluated in clinical settings. If AATASO treatment does negatively impact lung disease in patients with PiZZ, AAT replacement therapy is available and could be used in combination with AAT-ASO. 
AAT-ASO reduces both wild-type and mutant $h A A T$, since the target population is mainly homozygous patients with PiZZ. The association between heterozygosity of AAT mutant alleles and the risk of chronic liver disease is still controversial. If the need arises for the treatment of heterozygous patients (PiMZ) or compound heterozygous patients (e.g., PiSZ), a Z allele-specific ASO could be designed as demonstrated previously with mutant Huntingtin $(59,60)$.

In summary, AATD liver disease is an underdiagnosed, rare genetic disease with significant unmet medical need. Here, we demonstrated that ASO treatment reduces mutant protein aggregation in the liver and ameliorates liver fibrosis in adult PiZ mice. Moreover, we showed that treatment prevents mutant protein aggregation and liver injury in young mice. Our data indicate that this treatment might benefit both pediatric and adult AATD patients with liver disease.

\section{Methods}

Cell culture and transfection. Human HCC cell line HepG2 cells (ATCC) were cultured in MEM containing 1\% L-glutamine, $10 \%$ fetal bovine serum, and 100 units $/ \mathrm{ml}$ penicillin/streptomycin in $5 \% \mathrm{CO}_{2}$ at $37^{\circ} \mathrm{C}$. Mouse primary hepatocytes were prepared using standard collagenase procedure as described previously (61). Cynomolgus primary hepatocytes were purchased from Celsis In Vitro Technologies. Electroporation of ASOs was carried out with optimized conditions using the HT-200 BTX Electroporator with the ElectroSquare Porator (ECM 830) voltage source in 96-well electroporation plates (BTX, Harvard Apparatus, $2 \mathrm{~mm}$ ). Cells were harvested approximately 16 hours after electroporation.

ASOs. All oligonucleotides used in these studies were 20 nucleotides in length and chemically modified with phosphorothioate in the backbone and 2'-O-methoxyethyl on the wings, with a central deoxy gap (5-10-5 gapmer). Oligonucleotides were synthesized using an Applied Biosystems 380B automated DNA synthesizer (PerkinElmer Life and Analytical Sciences, Applied Biosystems) and purified as previously described (35).

Animal experiments. PiZ mice were generated and described previously (15). The animals were housed in microisolator cages on a constant 12-hourlight/dark cycle with controlled temperature and humidity and were given access to normal chow and water ad libitum. Animals were injected subcutaneously twice per week with AAT-ASO, control ASO, or vehicle PBS for periods of time indicated above.

The cynomolgus monkey study was performed at Korean Institute of Toxicology (Daejeong, Republic of Korea), and all procedures were approved by its local animal use committee. The animals were injected subcutaneously at $25 \mathrm{mg} / \mathrm{kg} 3$ times for the first week and twice per week for weeks 2 to 12 . Animals were individually housed in a controlled environment with constant temperature $\left(21^{\circ} \mathrm{C}\right)$ and a 12 -hour-light/dark cycle. Food and water were available ad libitum, except during collection of blood samples, in which case animals were fasted overnight.

Plasma chemistry analysis. Blood samples were collected by tail nick in mice and venipuncture of cephalic, saphenous, or femoral veins in monkeys. Plasma AAT levels and chemistry values were measured on the AU480 Clinical Chemistry Analyzer (Beckman Coulter). Monkey AAT was determined with Beckman Coulter hAAT assay. Due to strong cross-reactivity of this human assay with mouse AAT, a custom assay with DiaSorin Alpha-1 Antitrypsin reagent set was established and validated on the clinical analyzer using immunoturbidity method. This DiaSorin antibody showed minimal reactivity to mouse AAT, so mouse average endogenous AAT values were determined in normal mice and subtracted from the total AAT in PiZ mice to obtain hAAT values.

Quantitative real-time PCR. Cultured cells were lysed and the total RNA was extracted with Qiagen RNeasy columns. Animal tissues were homogenized in Guanidine Isothiocyanate solution (Invitrogen) supplemented with 8\% 2-mercaptoethanol (Sigma-Aldrich). Total RNA was prepared according to the RNeasy mini Kit (Qiagen). Quantitative real-time PCR (qRT-PCR) was performed using an ABI Prism 7700 sequence detector (Applied Biosystems). The sequences of primers and probes used in this study are as follows: hAAT, forward, 5'-GGAGATGCTGCCCAGAAGAC-3', reverse, 5'-GCTGGCGGTATAGGCTGAAG-3', probe, 5'-Fam-ATCAGGATCACCCAACCTTCAACAAGATCA-Tamra-5'; monkey AAT, 5'-TCTTTAAAGGCAAATGGGAGAGA-3', reverse, 5'-TGCCTAAACGCCTCATCATG-3', probe, 5'-Fam-CCACGTGGACCAGGCGACCA-Tamra-5'; mouse TIMP1, 5'-TCATGGAAAGCCTCTGTGGAT-3', reverse, 5'-GCGGCCCGTGATGAGA-3', probe, 5'-Fam-CCCACAAGTCCCAGAACCGCAGTG-Tamra-5'; collagen type $1 \propto 1,5^{\prime}$-GGGCGAGTGCTGTGCTTT-3', reverse, 5'-GGGTCCCTCGACTCCTACATC-3', probe, 5'-Fam-CCCGGAAGAATACGTATCACCAAACTCAGA-IOWA-BLACK-5' (with internal ZEN); collagen type $3 \alpha 1$, 5'-CACAGCAGTCCAACGTAGATGAA-3', reverse, 5'-TGACATGGTTCTGGCTTCCA-3', probe, 5'-Fam-TGCAGCCACCTTGGTCAGTCCTATGAG-IOWA-BLACK-5' (with internal ZEN); MMP2, 5' -TGAAGTTTGGAAGCATCAAATCA-3', reverse, 5'-AGGCTGCTTCACATCCTTCAC-3', probe, 5'-Fam-CGGGCCCTATCATCTTCATCG-Tamra-5'; MMP9, forward, 5'-CACCTTCACCCGCGTGTAC-3', reverse, 5'-GCTCCGCGACACCAAACT-3', probe, 5'-Fam-ACCCGAAGCGGACATTGTCATC-Tamra-5'; and smooth muscle actin, forward, 5'-TGCCTCTAGCACACAACTGTGA-3', reverse, 5'-GCAGGAATGATTTGGAAAGGAA-3', probe, 5'-FamCGTTTTGTGGATCAGCGCCTCCA-Tamra-5'. Additional primer sequences are listed in Supplemental Table 1.

Protein expression analysis. Liver soluble and aggregated AAT was separated as described previously (39). Briefly, the tissue was homogenized in a prechilled Dounce homogenizer for 30 repetitions and then passed through a 28-gauge needle 10 times. The total protein concentration was determined, and a $5-\mu \mathrm{g}$ total liver protein sample was aliquoted and centrifuged at $10,000 \mathrm{~g}$ for 30 minutes at $4{ }^{\circ} \mathrm{C}$. Supernatant was immediately removed, and the insoluble protein was denatured and solubilized. Both fractions were separated on SDS-PAGE; equal amounts of total liver protein were loaded per soluble-insoluble pair in quantitative experiments. AAT protein was detected by a polyclonal antibody against hAAT purchased from DiaSorin Inc., and the secondary antibody was HRP-conjugated rabbit anti-goat antibody (Jackson ImmunoResearch). GAPDH was detected using a monoclonal antibody from Advanced Immunochemical Inc. Western blot was quantitated with ImageQuant. $\alpha$-SMA Western blot was carried out with a monoclonal antibody purchased from Sigma-Aldrich. Both GAPDH and $\alpha$-SMA antibodies were detected with horse anti-mouse secondary antibody from Cell Signaling. IHC analysis. Animal tissues were collected, fixed in $10 \%$ buffered formalin, and paraffin embedded. Sections were stained with PAS-D for AAT aggregates; AAT IHC for hAAT; Sirius red for fibrosis; $\alpha$-SMA for activated stellate cells; ASO IHC for ASO uptake; and RNA in situ hybridization using QuantiGene ViewRNA Assay (Affymetrix). The following antibodies were used for immunostaining: anti-hAAT (Dako), anti- $\alpha$-SMA (Abcam), and anti-ASO (Isis Pharmaceuticals).

Hydroxyproline assay. Liver hydroxyproline content was determined as described previously (62). Briefly, approximately $100 \mathrm{mg}$ liver tissue was homogenized in $1 \mathrm{ml} 6 \mathrm{~N} \mathrm{HCL}$ and hydrolyzed at $110^{\circ} \mathrm{C}$ for 18 hours. A $25-\mu \mathrm{l}$ aliquot was dried at $60^{\circ} \mathrm{C}$, and the sediment was then dissolved in $1.2 \mathrm{ml} 50 \%$ isopropanol and incubated with $200 \mu \mathrm{l} 0.56 \%$ chloramines T solution (Sigma-Aldrich) in acetate citrate buffer ( $\mathrm{pH}$ 6.0) for 10 minutes at room temperature. Finally, $1 \mathrm{ml}$ Ehrlich's reagent was added, and the mixture was incubated at $50^{\circ} \mathrm{C}$ for 90 minutes. After cooling, the absorbance at $558 \mathrm{~nm}$ was measured.

Statistics. As specified in each figure legend, 1-way ANOVA with Tukey's comparisons, 2-way ANOVA with Bonferroni's post-hoc tests, or 1-tailed Student's $t$ test (paired analysis) were used for statistical analyses in this study. $P$ values less than 0.05 were considered significant. 
Study approval. All animal husbandry and procedures were approved by the Institutional Animal Care and Use Committee at Isis Pharmaceuticals.

\section{Acknowledgments}

The authors would like to thank Tracy Reigle for her help with formatting the figures and Maheen David for her assistance in manuscript submission.
Received for publication November 27, 2012, and accepted in revised form October 15, 2013.

Address correspondence to: Brett P. Monia, Isis Pharmaceuticals, 2855 Gazelle Ct., Carlsbad, California 92010, USA. Phone: 760.603.2350; Fax: 760.603.2502; E-mail: bmonia@ isisph.com.
1. Janciauskiene SM, Bals R, Koczulla R, Vogelmeier C, Kohnlein T, Welte T. The discovery of alpha1-antitrypsin and its role in health and disease. Respir Med. 2011;105(8):1129-1139.

2. Ekeowa UI, et al. $\alpha 1$-Antitrypsin deficiency, chronic obstructive pulmonary disease and the serpinopathies. Clin Sci (Lond). 2009;116(12):837-850.

3. Greene CM, et al. $\alpha-1$ Antitrypsin deficiency: a conformational disease associated with lung and liver manifestations. J Inherit Metab Dis. 2008;31(1):21-34.

4. Bals R. $\alpha$-1-Antitrypsin deficiency. Best Pract Res Clin Gastroenterol. 2010;24(5):629-633.

5. Teckman JH, Lindblad D. $\alpha$-1-Antitrypsin deficiency: diagnosis, pathophysiology, and management. Curr Gastroenterol Rep. 2006;8(1):14-20.

6. Silverman EK, Sandhaus RA. Clinical practice. a1-Antitrypsin deficiency. $N$ Engl J Med. 2009; 360(26):2749-2757.

7. Fregonese L, Stolk J. Hereditary $\alpha$-1-antitrypsin deficiency and its clinical consequences. Orphanet J Rare Dis. 2008;3:16.

8. Gooptu B, Ekeowa UI, Lomas DA. Mechanisms of emphysema in $\alpha$-1-antitrypsin deficiency: molecular and cellular insights. Eur RespirJ. 2009;34(2):475-488.

9. Hogarth DK, Rachelefsky G. Screening and familial testing of patients for $\alpha$-1-antitrypsin deficiency. Chest. 2008;133(4):981-988.

10. Lomas DA, Evans DL, Finch JT, Carrell RW. The mechanism of $Z \alpha$-1-antitrypsin accumulation in the liver. Nature. 1992;357(6379):605-607.

11. Ekeowa UI, et al. Defining the mechanism of polymerization in the serpinopathies. Proc Natl Acad Sci US A. 2010;107(40):17146-17151.

12. Nelson DR, Teckman J, Di Bisceglie AM, Brenner DA. Diagnosis and management of patients with $\alpha$-1-antitrypsin (A1AT) deficiency. Clin Gastroenterol Hepatol. 2012;10(6):575-580.

13. Fairbanks KD, Tavill AS. Liver disease in $\alpha$-1-antitrypsin deficiency: a review. Am J Gastroenterol. 2008;103(8):2136-2141.

14. Esquivel CO, et al. Indications for pediatric liver transplantation. J Pediatr. 1987;111(6 pt 2):1039-1045.

15. Carlson JA, et al. Accumulation of PiZ $\alpha$-1-antitrypsin causes liver damage in transgenic mice.J Clin Invest. 1989;83(4):1183-1190.

16. Ali R, et al. Evaluation of a transgenic mouse model for $\alpha$-1-antitrypsin (AAT) related liver disease. Ann Hum Genet. 1994;58(pt 4):305-320.

17. Ruther U, Tripodi M, Cortese R, Wagner EF. The human $\alpha$-1-antitrypsin gene is efficiently expressed from two tissue-specific promotors in transgenic mice. Nucleic Acids Res. 1987;15(18):7519-7529.

18. Dycaico MJ, et al. Neonatal hepatitis induced by $\alpha$-1-antitrypsin: a transgenic mouse model. Science. 1988;242(4884):1409-1412.

19. Sifers RN, Carlson JA, Clift SM, DeMayo FJ, Bullock DW, Woo SL. Tissue specific expression of the human $\alpha$-1-antitrypsin gene in transgenic mice. Nucleic Acids Res. 1987;15(4):1459-1475.

20. Sifers RN, Finegold MJ, Woo SL. $\alpha$-1-Antitrypsin deficiency: accumulation or degradation of mutant variants within the hepatic endoplasmic reticulum. Am J Respir Cell Mol Biol. 1989;1(5):341-345.

21. Qu D, Teckman JH, Omura S, Perlmutter DH Degradation of a mutant secretory protein, $\alpha$-1-antitrypsin $Z$, in the endoplasmic reticulum requires proteasome activity. J Biol Chem. 1996; 271(37):22791-22795.
22. Teckman JH, Perlmutter DH. The endoplasmic reticulum degradation pathway for mutant secretory proteins $\alpha$-1-antitrypsin $Z$ and $S$ is distinct from that for an unassembled membrane protein. J Biol Chem. 1996;271(22):13215-13220.

23. Teckman JH, Perlmutter DH. Retention of mutant $\alpha(1)$-antitrypsin $Z$ in endoplasmic reticulum is associated with an autophagic response. Am J Physiol Gastrointest Liver Physiol. 2000;279(5):G961-G974.

24. Wu Y, Whitman I, Molmenti E, Moore K, Hippenmeyer P, Perlmutter DH. A lag in intracellular degradation of mutant $\alpha$-1-antitrypsin correlates with the liver disease phenotype in homozygous PiZZ alpha 1-antitrypsin deficiency. Proc Natl Acad Sci US A. 1994;91(19):9014-9018.

25. Lindblad D, Blomenkamp K, Teckman J. $\alpha$-1-Antitrypsin mutant $Z$ protein content in individual hepatocytes correlates with cell death in a mouse model. Hepatology. 2007;46(4):1228-1235.

26. Marcus NY, et al. Characteristics of hepatocellular carcinoma in a murine model of $\alpha$-1-antitrypsin deficiency. Hepatol Res. 2010;40(6):641-653.

27. Rudnick DA, Perlmutter DH. $\alpha$-1-Antitrypsin deficiency: a new paradigm for hepatocellular carcinoma in genetic liver disease. Hepatology. 2005;42(3):514-521.

28. Perlmutter DH, Silverman GA. Hepatic fibrosis and carcinogenesis in alpha1-antitrypsin deficiency: a prototype for chronic tissue damage in gain-of-function disorders. Cold Spring Harb Perspect Biol. 2011;3(3).pii:a005801.

29. Hidvegi T, et al. An autophagy-enhancing drug promotes degradation of mutant $\alpha$-1-antitrypsin $Z$ and reduces hepatic fibrosis. Science. 2010; 329(5988):229-232.

30. Mencin A, et al. $\alpha-1$ Antitrypsin $Z$ protein (PiZ) increases hepatic fibrosis in a murine model of cholestasis. Hepatology. 2007;46(5):1443-1452.

31. Rudnick DA, Liao Y, An JK, Muglia LJ, Perlmutter $\mathrm{DH}$, Teckman JH. Analyses of hepatocellular proliferation in a mouse model of $\alpha$-1-antitrypsin deficiency. Hepatology. 2004;39(4):1048-1055.

32. Teckman JH, An JK, Loethen S, Perlmutter DH Fasting in $\alpha$-1-antitrypsin deficient liver: constitutive [correction of consultative] activation of autophagy. Am J Physiol Gastrointest Liver Physiol. 2002;283(5):G1156-G1165.

33. Rudnick DA, Shikapwashya O, Blomenkamp K, Teckman JH. Indomethacin increases liver damage in a murine model of liver injury from $\alpha$-1-antitrypsin deficiency. Hepatology. 2006;44(4):976-982.

34. Cruz PE, et al. In vivo post-transcriptional gene silencing of $\alpha-1$ antitrypsin by adeno-associated virus vectors expressing siRNA. Lab Invest. 2007; 87(9):893-902.

35. Bennett CF, Swayze EE. RNA targeting therapeutics: molecular mechanisms of antisense oligonucleotides as a therapeutic platform. Annu Rev Pharmacol Toxicol. 2010;50:259-293.

36. Dickens JA, Lomas DA. Why has it been so difficult to prove the efficacy of $\alpha$-1-antitrypsin replacement therapy? Insights from the study of disease pathogenesis. Drug Des Devel Ther. 2011;5:391-405.

37. Monia BP, Johnston JF, Ecker DJ, Zounes MA, Lima WF, Freier SM. Selective inhibition of mutant Ha-ras mRNA expression by antisense oligonucleotides. J Biol Chem. 1992;267(28):19954-19962.

38. Monia BP, et al. Sequence-specific antitumor activ- ity of a phosphorothioate oligodeoxyribonucleotide targeted to human C-raf kinase supports an antisense mechanism of action in vivo. Proc Natl Acad Sci US A. 1996;93(26):15481-15484.

39. An JK, Blomenkamp K, Lindblad D, Teckman JH. Quantitative isolation of $\alpha$ lAT mutant $Z$ protein polymers from human and mouse livers and the effect of heat. Hepatology. 2005;41(1):160-167.

40. Crooke RM, Graham MJ. Suborgan pharmacokinetics. In: Stanley TC, ed. Antisense Drug Technology: Principles, Strategies, and Applications. New York, New York, USA: Marcel Dekker; 2001:155-182.

41. Koller E, Vincent TM, Chappell A, De S, Manoharan $\mathrm{M}$, Bennett $\mathrm{CF}$. Mechanisms of singlestranded phosphorothioate modified antisense oligonucleotide accumulation in hepatocytes. Nucleic Acids Res. 2011;39(11):4795-4807.

42. Stoller JK, Fromer L, Brantly M, Stocks J, Strange C. Primary care diagnosis of $\alpha-1$ antitrypsin deficiency: issues and opportunities. Cleve Clin J Med. 2007;74(12):869-874.

43. Lomas DA. The selective advantage of $\alpha$-1-antitrypsin deficiency. Am J Respir Crit Care Med. 2006; 173(10):1072-1077.

44. Sveger T. The natural history of liver disease in $\alpha$ 1-antitrypsin deficient children. Acta Paediatr Scand. 1988;77(6):847-851.

45. Eriksson S. $\alpha$ 1-Antitrypsin deficiency and liver cirrhosis in adults. An analysis of 35 Swedish autopsied cases. Acta Med Scand. 1987;221(5):461-467.

46. Clark VC, Dhanasekaran R, Brantly M, Rouhani F, Schreck P, Nelson DR. Liver test results do not identify liver disease in adults with $\alpha(1)$-antitrypsin deficiency. Clin Gastroenterol Hepatol. 2012; 10(11):1278-1283.

47. Bowlus CL, et al. Factors associated with advanced liver disease in adults with $\alpha 1$-antitrypsin deficiency. Clin Gastroenterol Hepatol. 2005; 3(4):390-396.

48. Hidvegi T, Mukherjee A, Ewing M, Kemp C, Perlmutter DH. The role of autophagy in $\alpha$-1-antitrypsin deficiency. Methods Enzymol. 2011;499:33-54.

49. Marciniak SJ, Lomas DA. $\alpha 1$-Antitrypsin deficiency and autophagy. $N$ Engl J Med. 2010; 363(19):1863-1864.

50 . Yusa K, et al. Targeted gene correction of $\alpha 1$-antitrypsin deficiency in induced pluripotent stem cells. Nature. 2011;478(7369):391-394.

51. Mueller C, et al. Sustained miRNA-mediated knockdown of mutant AAT with simultaneous augmentation of wild-type AAT has minimal effect on global liver miRNA profiles. Mol Ther. 2012;20(3):590-600.

52. Alam S, Wang J, Janciauskiene S, Mahadeva R. Preventing and reversing the cellular consequences of $\mathrm{Z} \alpha-1$ antitrypsin accumulation by targeting s $4 \mathrm{~A}$. J Hepatol. 2012;57(1):116-124.

53. Burrows JA, Willis LK, Perlmutter DH. Chemical chaperones mediate increased secretion of mutant $\alpha$ 1-antitrypsin ( $\alpha$ 1-AT) Z: A potential pharmacological strategy for prevention of liver injury and emphysema in a 1-AT deficiency. Proc Natl Acad Sci US A. 2000;97(4):1796-1801.

54. Raal FJ, et al. Mipomersen, an apolipoprotein B synthesis inhibitor, for lowering of LDL cholesterol concentrations in patients with homozygous familial hypercholesterolaemia: a randomised, double-blind, placebo-controlled trial. Lancet. 
2010;375(9719):998-1006.

55. Crooke ST, Geary RS. Clinical pharmacological properties of mipomersen (Kynamro), a second generation antisense inhibitor of apolipoprotein B. Br J Clin Pharmacol. 2013;76(2):269-276.

56. Lomas DA, Evans DL, Stone SR, Chang WS, Carrell RW. Effect of the $Z$ mutation on the physical and inhibitory properties of $\alpha 1$-antitrypsin. Biochemistry. 1993;32(2):500-508.

57. Mahadeva $\mathrm{R}$, et al. Polymers of $\mathrm{Z} \alpha 1$-antitrypsin co-localize with neutrophils in emphysematous alveoli and are chemotactic in vivo. Am J Pathol. 2005;166(2):377-386.

58. Fregonese L, Stolk J, Frants RR, Veldhuisen B. $\alpha-1$ Antitrypsin Null mutations and severity of emphysema. Respir Med. 2008;102(6):876-884.

59. Carroll JB, et al. Potent and selective antisense oligonucleotides targeting single-nucleotide polymorphisms in the Huntington disease gene/allele-specific silencing of mutant huntingtin. Mol Ther.
2011;19(12):2178-2185.

60. Yu D, et al. Single-stranded RNAs use RNAi to potently and allele-selectively inhibit mutant huntingtin expression. Cell. 2012;150(5):895-908.

61. Quistorff B, Dich J, Grunnet N. Preparation of isolated rat liver hepatocytes. Methods Mol Biol. 1990;5:151-160.

62. Jamall IS, Finelli VN, Que Hee SS. A simple method to determine nanogram levels of 4-hydroxyproline in biological tissues. Anal Biochem. 1981;112(1):70-75. 